Provided for non-commercial research and education use. Not for reproduction, distribution or commercial use.

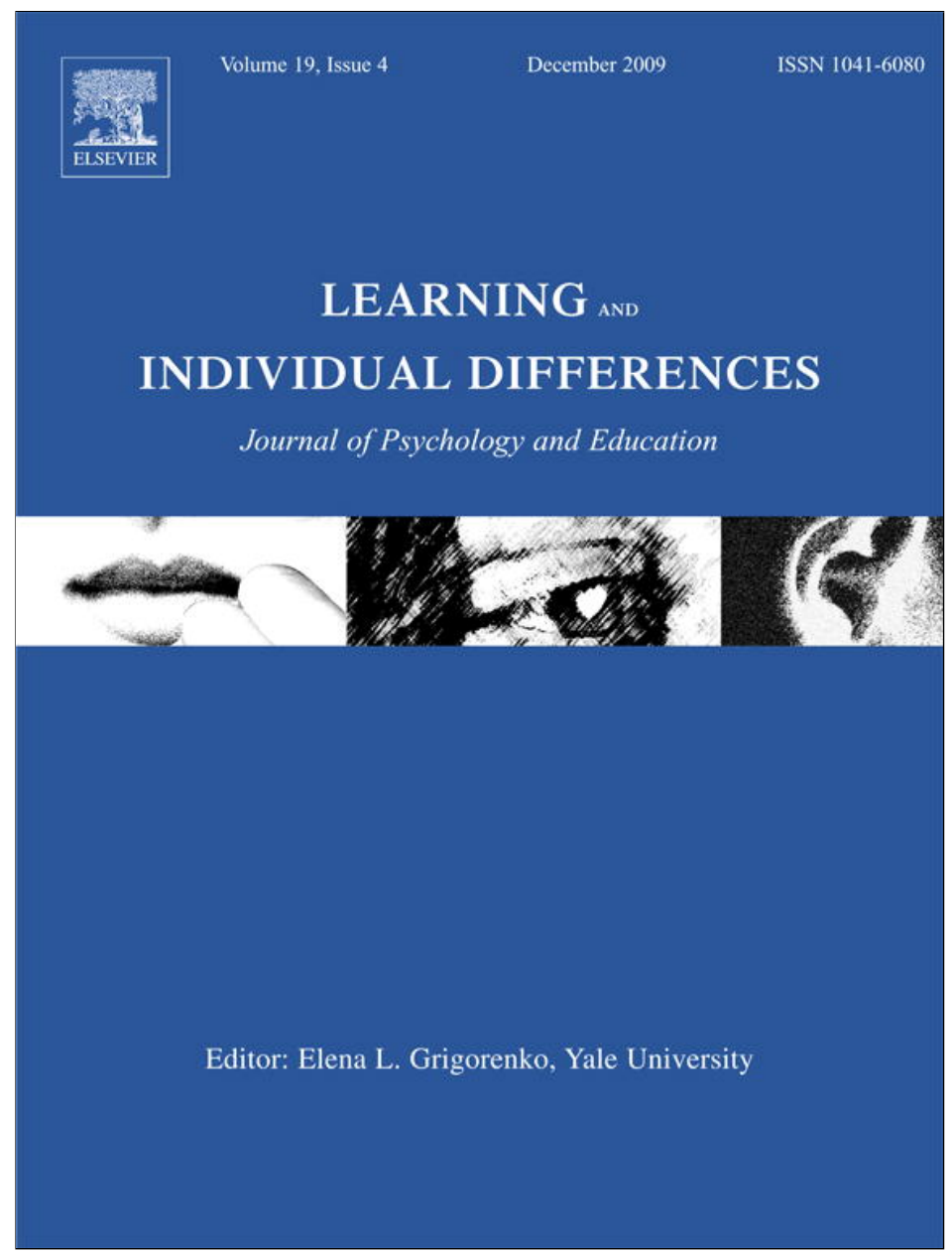

This article appeared in a journal published by Elsevier. The attached copy is furnished to the author for internal non-commercial research and education use, including for instruction at the authors institution and sharing with colleagues.

Other uses, including reproduction and distribution, or selling or licensing copies, or posting to personal, institutional or third party websites are prohibited.

In most cases authors are permitted to post their version of the article (e.g. in Word or Tex form) to their personal website or institutional repository. Authors requiring further information regarding Elsevier's archiving and manuscript policies are encouraged to visit:

http://www.elsevier.com/copyright 
Short report

\title{
Transition to school: The role of kindergarten children's behavior regulation is
}

\author{
Antje von Suchodoletz ${ }^{\text {a, }}$, Gisela Trommsdorff ${ }^{a}$, Tobias Heikamp ${ }^{\text {a }}$, Frank Wieber ${ }^{\text {a }}$, Peter M. Gollwitzer ${ }^{\text {a,b }}$ \\ a Department of Psychology, Post Box D14, University of Konstanz, 78457 Konstanz, Germany \\ ${ }^{\mathrm{b}}$ Department of Psychology, New York University, United States
}

\section{A R T I C L E I N F O}

\section{Article history:}

Received 10 April 2008

Received in revised 14 July 2009

Accepted 22 July 2009

\section{Keywords:}

Behavior regulation

Transition to school

Academic performance

Social behavior

\section{Introduction}

The transition to school is seen as an extensive process of adaptation during which children need to adjust to school standards. Successful adaptation is reflected in children's classroom behavior (i.e., prosocial behavior rather than behavior problems) and academic performance (Petriwskyj, Thorpe, \& Tayler, 2005). It is well documented that cognitive abilities (i.e., IQ) are linked to academic indicators of success in school (e.g., Deary, Strand, Smith, \& Fernandes, 2007). Recently, however, Duckworth and Seligman (2005) presented evidence that the ability to self-regulate has greater influence on a student's academic performance than his or her IQ. Self-regulation (the motivation and ability to control one's emotions and behaviors in potentially stressful situations) affects children's ability to adapt to and learn in formal school settings (Trommsdorff, in press). In this study, we refer to self-regulatory

\footnotetext{
th This research was financed by a grant from the German Research Foundation (DFG GZ, TR 169/14-2). This study is part of the projects "Developmental Conditions of Intentionality and its Limits" (Principal Investigator: Prof. Dr. Gisela Trommsdorff) and "The Limits of Action Control by Implementation Intentions" (Principal Investigator: Prof. Dr. Peter M. Gollwitzer) within the interdisciplinary research group "Limits of Intentionality" at the University of Konstanz, Germany. The authors wish to thank all the children, mothers, and teachers who participated or contributed to this project as well as the students at the University of Konstanz who assisted in the study. We thank Elizabeth Buckley-Reitz, Pennsylvania State University, United States, for her valuable comments on earlier drafts and Willy Nagl, University of Konstanz, for statistic advices. We also wish to thank the anonymous reviewers for their suggestions to improve the manuscript.

* Corresponding author. Now at: University of Freiburg, Research Group "The Empirics of Education", Department of Economic and Behavioral Sciences, Starkenstr. 44, 79085 Freiburg, Germany. Tel.: +49 761 2033005; fax: +49 7612033100.

E-mail addresses: antje.von.suchodoletz@psychologie.uni-freiburg.de (A. von Suchodoletz), gisela.trommsdorff@uni-konstanz.de (G. Trommsdorff), tobias.heikamp@uni-konstanz.de (T. Heikamp), frank.wieber@uni-konstanz.de (F. Wieber), peter.gollwitzer@uni-konstanz.de (P.M. Gollwitzer).
}

skills such as delaying gratification, following instructions, and inhibiting impulsive or aggressive behavior as behavior regulation (Kopp, 1982).

The development of behavior regulation is influenced by the family environment (Calkins \& Howse, 2004; Suchodoletz, Trommsdorff, \& Heikamp, submitted for publication). As a result, significant differences in behavior regulation exist among children when they enter formal schooling among other things (McClelland et al., 2007; Ponitz et al., 2008). Deficits in behavior regulation may cause social and academic adjustment difficulties in school (Calkins \& Howse, 2004; Eisenberg et al., 2000; McClelland, Morrison, \& Holmes, 2000). Therefore, it is important to understand the function of behavior regulation during the transition process.

\subsection{Behavior regulation and classroom behavior}

Behavior regulation enables children to adapt successfully to the classroom by means of their improved motivation and ability to pay attention to, remember, and follow classroom rules and teachers' demands (McClelland et al., 2007). Whereas externalizing problem behaviors are negatively related to behavior regulation skills (e.g., Eisenberg et al., 2000), social competence (Mischel, Shoda, \& Rodriguez, 1989) and peer status (Spinrad et al., 2006) are positively related to behavior regulation.

\subsection{Behavior regulation and academic performance}

Behavior regulation is positively related to children's school readiness, including emergent vocabulary, literacy, and math skills (McClelland et al., 2007). In addition, behavior regulation accounts for developmental changes in children's performance over the school year. In a study by Duckworth and Seligman (2005), performance in a delay-of-gratification task predicted academic performance (i.e., achievement-test scores) of adolescents more robustly than measures 
of intelligence did. In the current study, it was considered to be important to control for the influence of other child characteristics (such as vocabulary knowledge and mental concentration) and mother's level of education, which are presumed to be related to academic performance (e.g., Magnuson, 2007; Nelson \& Stage, 2007).

\subsection{Classroom behavior and academic performance}

Children's classroom behavior in the early school setting is closely related to their adjustment to school (Ladd \& Burgess, 2001) and is an important determinant of academic progress. School-related problem behaviors such as inattentiveness or oppositional behavior affect school readiness (Fantuzzo et al., 2007) and academic performance (Rabiner, Murray, Schmid, \& Malone, 2004). Moreover, academic underachievement may result in decreased achievement motivation (e.g., Preckel, Holling, \& Vock, 2006) and behavior problems (e.g., Kniveton, 1998).

\subsection{The present study}

The present study aims to test the relationship between behavior regulation in kindergarten and adaptation to school in first grade. Here, we extend the research of McClelland and others (e.g., McClelland et al., 2007) by observing children at the transition to formal schooling. Additionally, we focus on academic and social indicators of successful adaptation. We hypothesize that behavior regulation in kindergarten will predict first grade academic performance (H1) and classroom behavior (H2). We also expect that children's classroom behavior will relate to their academic performance (H3).

\section{Methods}

\subsection{Participants}

Data analyses were conducted on observations of 28 German children ( 16 boys, 12 girls) from public kindergartens. Of the original sample $(N=64), 36$ participants (56\%) took part in the follow-up study at the end of first grade. Eight subjects were excluded because of missing data. Mann-Whitney $U$ analyses revealed that there was no selective dropout between children who were retained and those who did not participate in the follow-up with respect to behavior regulation.

When first observed, children were between 5.4 and 6.5 years old $(M=5.9, \mathrm{SD}=0.3)$. The majority of the children lived in families with a middle-class socio-economic background. Using ISCED-97 (Organization for Economic Co-operation and Development, 1999) to indicate mother's level of education, 17 mothers (61\%) had completed the first stage of tertiary education (i.e., B.A. or M.A.).

\subsection{Procedure}

In the spring of their last kindergarten year (German children attend three years of kindergarten, from ages 3 to 6 ) the children were observed in different behavior regulation tasks while their mothers completed questionnaires on demographic information. One-year follow-up measures at the end of first grade (in Germany, the school year starts in September) included formal tests of academic performance, language skills, nonverbal intelligence, and a computer-based mental concentration test. Teacher reports of children's classroom behavior and school progress were also assessed at the end of first grade.

\subsection{Measures}

\subsubsection{Assessment of behavior regulation}

Behavior regulation was measured using the Snack Delay and Tower of Patience tasks of the Laboratory Temperament Assessment Battery-Preschool Version (Lab-TAB; Goldsmith, Reilly, Lemery, Longley, \& Prescott, 1993). In the Snack Delay, task the child must resist the temptation to eat a candy until the experimenter rings a bell. In the Tower of Patience task, the child must take turns with the experimenter in building a tower. Both tasks use multiple trials with waiting periods of different duration for each of the trials. The tasks measure the child's motivation and ability to keep a rule in mind, respond according to the rule, and to inhibit a dominant spontaneous response. These tasks have been widely used in previous studies to assess behavior regulation (review by Garon, Bryson, \& Smith, 2008). Overall possible scores in the Snack Delay task ranged from zero to six; Tower of Patience scores ranged from zero to 14 (i.e., for each trial, a rule violation was coded as one point, no rule violation as zero). For statistical analyses, variables were recoded, zero corresponding to low level of behavior regulation and six (or 14, respectively) to a high level. Videos were coded by two independent raters; interrater reliabilities (based on $30 \%$ of the videotapes) were high for both tasks ( $\kappa=.87$ and .90 , respectively).

\subsubsection{Assessment of adaptation to school: Academic performance}

Using the Salzburger Reading and Writing Test (SLRT; Landerl, Wimmer, \& Moser, 1997), we averaged reading time (in seconds) and reading errors for each subtest (Common Valid Words (e.g., cat), NonWords (e.g., talire), and a Short Text of 30 words) to assess reading skills. Writing skills were assessed by subtracting the number of words with phonetic errors from those correctly written (out of a sample of fifteen common German words, like "hand"). A mean score was derived by averaging the test variables (reading time, reading errors, and writing score). The subtests Addition, Subtraction, and Component Comprehension of the German Test of Mathematics for the First Grade (DEMAT1+; Krajewski, Küspert, \& Schneider, 2002) assessed mathematic performance. To create a total score, the sum scores within each subtest were averaged.

Additionally, teachers evaluated student performance in mathematics and reading and writing skills in terms of German school grades. Test scores and school grades were recoded (for all variables, a higher score indicated better academic performance) and standardized by computing $z$-scores. As Spearman rank correlations revealed, test scores and teacher evaluations of academic performance were correlated $(r=.52, p<.01$ for mathematic performance; $r=.57, p<.01$ for reading and writing skills). Consequently, test scores and teacher evaluations for each child in mathematic performance and in reading and writing skills were averaged.

\subsubsection{Assessment of adaptation to school: Classroom behavior}

The Strengths and Difficulties Questionnaire (SDQ, teacher version; Goodman, 1997; German Version by Woerner et al., 2002) is a reliable and well established instrument to measure behavior problems (i.e., emotional problems, conduct problems, hyperactivity-inattention problems, and peer-relationship problems) and prosocial behavior. Even though the SDQ is a brief behavior screener, a meta-analysis by Warnick, Bracken, and Kasl (2008) supports the use of the SDQ in community samples. Cronbach's Alphas for the subscales ranged from .71 to .88 . A total score for behavior problems (Cronbach's Alpha $=.81$ ) was derived by adding the scale scores of the four problem scales (see Klasen, Woerner, Rothenberger, \& Goodman, 2003). The score was recoded, with lower values indicating fewer behavior problems.

\subsubsection{Assessment of mental concentration}

A computerized discrimination task assessed the children's mental concentration. In 282 trials, children categorized transportation and animal pictures. After 12 exercise trials, the first mental concentration measurement (30 trials) followed. Subsequently, children worked through 210 trials of the same task with additional distractions before the second mental concentration measurement (30 trials) took place. A focused index for mental concentration was computed by subtracting the average reaction times of correct responses in measurement 2 from those in measurement 1 . Higher values thus reflect that a child 
Table 1

Descriptive statistics $(N=28)$.

\begin{tabular}{|c|c|c|c|c|c|c|c|}
\hline Measure and variable & $M$ & SD & Range & $v$ & $\sigma_{\mathrm{v}}$ & $\beta_{2}$ & $\sigma_{\beta 2}$ \\
\hline \multicolumn{8}{|l|}{ Behavior regulation } \\
\hline Snack delay & 2.18 & 1.70 & $0-6$ & 0.53 & 0.44 & -0.55 & 0.86 \\
\hline Tower of patience & 0.61 & 1.42 & $0-6$ & 2.67 & 0.44 & 7.32 & 0.86 \\
\hline \multicolumn{8}{|l|}{ Academic performance } \\
\hline Reading time (SLRT) & 55.65 & 27.68 & $\begin{array}{l}14.67- \\
130.00\end{array}$ & 1.33 & 0.44 & 1.99 & 0.86 \\
\hline Reading mistakes (SLRT) & 1.76 & 1.21 & $0-4.67$ & 0.52 & 0.44 & -0.34 & 0.86 \\
\hline $\begin{array}{l}\text { Correctly written } \\
\text { words (SLRT) }\end{array}$ & 7.32 & 3.53 & $0-15$ & 0.24 & 0.44 & -0.32 & 0.86 \\
\hline $\begin{array}{l}\text { Words with phonetic } \\
\text { errors (SLRT) }\end{array}$ & 1.32 & 2.63 & $0-10$ & 2.45 & 0.44 & 5.71 & 0.86 \\
\hline $\begin{array}{l}\text { Mathematics } \\
\quad(\text { DEMAT } 1+)\end{array}$ & 7.64 & 3.11 & $3-12$ & -0.14 & 0.44 & -1.29 & 0.86 \\
\hline $\begin{array}{l}\text { Teacher report } \\
\text { reading }^{\mathrm{a}}\end{array}$ & 2.23 & 0.83 & $1-4$ & 0.02 & 0.44 & -0.61 & 0.86 \\
\hline $\begin{array}{l}\text { Teacher report } \\
\text { writing }^{\mathrm{a}}\end{array}$ & 2.43 & 0.87 & $1-4$ & 0.15 & 0.44 & -0.75 & 0.86 \\
\hline $\begin{array}{c}\text { Teacher report } \\
\text { mathematics }\end{array}$ & 2.07 & 1.00 & $1-4$ & 0.85 & 0.45 & -0.09 & 0.87 \\
\hline \multicolumn{8}{|l|}{ Classroom behavior } \\
\hline $\begin{array}{l}\text { Prosocial behavior } \\
\text { (SDQ) }\end{array}$ & 7.25 & 2.35 & $3-10$ & -0.47 & 0.44 & -0.99 & 0.86 \\
\hline $\begin{array}{l}\text { Behavior problems } \\
\text { (SDQ) }\end{array}$ & 6.14 & 6.30 & $0-25$ & 1.26 & 0.44 & 1.35 & 0.86 \\
\hline \multicolumn{8}{|l|}{ Mental concentration } \\
\hline Measurement 1 & 6.69 & 0.18 & $\begin{array}{l}6.46- \\
7.05\end{array}$ & 0.77 & 0.46 & 0.41 & 0.90 \\
\hline Measurement 2 & 6.80 & 0.23 & $\begin{array}{l}6.48- \\
7.28\end{array}$ & 0.81 & 0.46 & -0.25 & 0.90 \\
\hline \multicolumn{8}{|l|}{ Language skills ${ }^{\mathrm{b}}$} \\
\hline $\begin{array}{l}\text { Comprehension } \\
\text { grammatical structures } \\
\text { (HSET) }\end{array}$ & 40.36 & 8.55 & $26-61$ & 0.21 & 0.44 & -0.37 & 0.86 \\
\hline $\begin{array}{l}\text { Imitation grammatical } \\
\text { structures (HSET) }\end{array}$ & 48.89 & 7.95 & $34-59$ & -0.42 & 0.44 & -0.92 & 0.86 \\
\hline \multicolumn{8}{|l|}{ Cognitive ability ${ }^{\mathrm{b}}$} \\
\hline CPM & 54.39 & 7.42 & $42-72$ & 0.38 & 0.44 & -0.44 & 0.86 \\
\hline
\end{tabular}

Note. Raw scores. Skewness $(v)$ and associated standard deviation $\left(\sigma_{\mathrm{v}}\right)$. Kurtosis $\left(\beta_{2}\right)$ and associated standard deviation $\left(\sigma_{\beta 2}\right)$.

a German grade-scale: 1 (very good), 2 (good), 3 (satisfactory), 4 (adequate), and 5 (inadequate).

b Age-standardized $T$-values. SLRT $=$ Salzburger Reading and Writing Test; DEMAT $1+=$ German Test of Mathematics for the 1st Grade; SDQ $=$ Strengths and Difficulties Questionnaire; HSET = Heidelberger Test of Language Development; $\mathrm{CPM}=$ Coloured Progressive Matrices.

was able to keep his or her mental concentration effectively focused on the discrimination task over time.

\subsubsection{Assessment of language skills}

Language skills were assessed with the Heidelberger Test of Language Development (HSET; Grimm \& Schöler, 1991). Expressive language skills were evaluated using the Imitation Grammatical
Structures subtest, and receptive language skills with the Comprehension Grammatical Structures subtest. The raw scores were transformed into age-standardized $T$-values and averaged to a single score reflecting language abilities.

\subsubsection{Assessment of cognitive ability}

Nonverbal intelligence and logical reasoning were assessed with the Coloured Progressive Matrices (CPM; Raven, Court, \& Raven, 1984; German Version by Bulheller \& Häcker, 2002). Sum scores were transformed into age-standardized $T$-values.

\subsection{Data analysis}

We computed Spearman rank correlations for correlational analyses and Mann-Whitney $U$-tests to test gender effects on all variables. Hypotheses were tested using partial least squares (PLS), applying SmartPLS 2.0 (Ringle, Wende, \& Will, 2005). PLS places minimal restrictions on measurement scales, sample size, and residual distributions (Chin, 1998). Model fit is estimated in two stages: first, the assessment of the reliability and validity of the measurement model, and second, the assessment of the structural model (Barklay, Higgins, \& Thompson, 1995). The bootstrap resampling procedure (see Yung \& Chan, 1999), using 500 randomly drawn subsamples that generated $t$-statistic values ( $n$ minus the number of estimated parameters, in which $n$ is equivalent to the sample size), was applied to test the significance of indicator loadings and path coefficients. For analyses, all variables were $z$-standardized. A reflective model with the direction of causality from the construct to the indicator (Jarvis, Mackenzie, \& Podsakoff, 2003) was used as latent measurement model. The indicators were created under the assumption that they all measured the same underlying construct (Chin, 1998).

\section{Results}

\subsection{Descriptive and correlational analysis}

Descriptive analyses were performed using raw scores. In general, the children demonstrated successful behavior regulation as indexed by the observational data. The range of the scores was rather small in the Tower of Patience task, but not in the Snack Delay task. To prevent the findings merely reflecting the behavior regulation of a minority of subjects, hypotheses testing was conducted on both tasks as indicators of behavior regulation. On average, the academic performance in the sample was good. Teachers characterized the children as generally prosocial, with only marginal behavior problems. The children's level of cognitive ability (i.e., nonverbal intelligence) and language skills were largely within the normal range. Children's reaction time increased from mental concentration measurement 1 to measurement 2 . Table 1 shows the descriptive statistics of the raw data for all variables.

Table 2

Spearman Rank Correlation Matrix $(N=28)$.

\begin{tabular}{|c|c|c|c|c|c|c|c|c|c|}
\hline & 2 & 3 & 4 & 5 & 6 & 7 & 8 & 9 & 10 \\
\hline 1) Snack delay & $.34^{\mathrm{a}}$ & $.49^{\mathrm{c}}$ & $.60^{\mathrm{c}}$ & -.01 & $-.34^{\mathrm{a}}$ & $.34^{\mathrm{a}}$ & -.12 & .09 & -.09 \\
\hline 2) Tower of patience & - & .26 & $.39^{\mathrm{b}}$ & .29 & -.25 & $.51^{\mathrm{c}}$ & .13 & .07 & .14 \\
\hline 3) Reading and writing skills & & - & $.48^{\mathrm{b}}$ & $.34^{\mathrm{b}}$ & $-.68^{\mathrm{c}}$ & .27 & .14 & -.05 & .16 \\
\hline 4) Mathematics & & & - & .11 & $-.51^{\mathrm{c}}$ & $.64^{\mathrm{c}}$ & -.17 & .11 & .04 \\
\hline 5) Prosocial behavior & & & & - & $-.57^{c}$ & .16 & -.10 & -.14 & $.42^{\mathrm{b}}$ \\
\hline 6) Behavior problems & & & & & - & $-.32^{\mathrm{a}}$ & .12 & .05 & $-.33^{\mathrm{a}}$ \\
\hline 7) Nonverbal intelligence & & & & & & - & .04 & .10 & .02 \\
\hline 8) Language skills & & & & & & & - & .20 & .20 \\
\hline 9) Mental concentration & & & & & & & & - & .02 \\
\hline 10) Mother's education & & & & & & & & & - \\
\hline
\end{tabular}


Table 3

Loadings, Reliability, Average Variance Extracted (AVE), and $t$-statistics.

\begin{tabular}{|c|c|c|c|c|c|}
\hline $\begin{array}{l}\text { Construct } \\
\text { and indicator }\end{array}$ & Loadings & $\begin{array}{l}\text { Composite } \\
\text { reliability } \\
\left(\rho_{\mathrm{c}}\right)\end{array}$ & $\begin{array}{l}\text { Average variance } \\
\text { extracted } \\
\text { (AVE) }\end{array}$ & $S E$ & $\begin{array}{l}t- \\
\text { statistic }\end{array}$ \\
\hline Behavior regulation & & .77 & .62 & & \\
\hline $\begin{array}{l}\text { Measure } 1 \\
\text { (Snack delay) }\end{array}$ & $.85^{\mathrm{a}}$ & & & .10 & 9.24 \\
\hline $\begin{array}{l}\text { Measure } 2 \\
\quad \text { (Tower of patience) }\end{array}$ & $.73^{\mathrm{a}}$ & & & .22 & 3.28 \\
\hline $\begin{array}{l}\text { Nonverbal } \\
\text { intelligence }\end{array}$ & & 1.00 & 1.00 & & \\
\hline Measure 1 (CPM) & 1.00 & & & .00 & \\
\hline $\begin{array}{l}\text { Academic } \\
\text { performance }\end{array}$ & & .86 & .76 & & \\
\hline $\begin{array}{l}\text { Reading and } \\
\text { writing skills }\end{array}$ & $.86^{\mathrm{a}}$ & & & .06 & 15.42 \\
\hline Mathematics & $.88^{\mathrm{a}}$ & & & .05 & 18.84 \\
\hline Classroom behavior & & .85 & .74 & & \\
\hline Prosocial behavior & $.74^{\mathrm{a}}$ & & & .22 & 3.59 \\
\hline Behavior problems & $.97^{\mathrm{a}}$ & & & .11 & 8.37 \\
\hline Mother's education & & 1.00 & 1.00 & & \\
\hline ISCED-97 index & 1.00 & & & .00 & \\
\hline
\end{tabular}

${ }^{a} p<.01$ (based on $t_{(23)}$, two-tailed test). $t_{(0.01 ; 23)}=3.10$.

Mann-Whitney $U$ analyses revealed no significant gender differences in behavior regulation, academic performance, or classroom behavior. Teacher evaluations of academic performance and standardized test scores (i.e., SLRT, DEMAT1+) both showed correlations to children's behavior regulation and classroom behavior in similar measures. The relationships between the dependent variables (i.e., academic performance, classroom behavior) and control variables were examined. The analyses yielded significant correlations between nonverbal intelligence and mathematic performance $(r=.64, p<.01)$ and between mother's level of education and prosocial behavior $(r=.42, p<.05)$. No relationships were found to language skills and mental concentration. Consequently, nonverbal intelligence and mother's level of education were entered as latent variables in further analyses. A summary of correlations is presented in Table 2 . The results were confirmed when computing the correlations without outliers.

\subsection{Partial least squares analyses}

\subsubsection{Evaluation of the measurement model}

Individual reflective-scale reliability is assessed by examining the loadings of the scales on the underlying construct. We accepted only scales with loadings higher than 0.7 (Carmines \& Zeller, 1979). All reliabilities were over the acceptable cut-off level. For reflective measures, the composite reliability $\left(\rho_{\mathrm{c}}\right)$ assesses construct reliability (Fornell \& Larcker, 1981). The composite reliabilities ranged from .77 (self-regulation) to .86 (academic performance). All were above the recommended 0.7 level (Nunnally, 1978). Convergent validity was measured by average extracted variance (AVE; Fornell \& Larcker, 1981). AVE should exceed 0.5; all constructs satisfied this condition. Discriminant validity was assessed by applying the square root of the AVE and should be at least 0.7 (Barklay et al., 1995; Chin, 1998). Additionally, the square root of the AVE should be greater than the
Table 5

Results of the structural model.

\begin{tabular}{llll}
\hline Hypothesis & $\beta$ & t-statistic (bootstrap) & Result of test \\
\hline H1 & $.54^{\mathrm{a}}$ & 6.48 & Supported \\
$\mathrm{H} 2$ & $.47^{\mathrm{a}}$ & 3.11 & Supported \\
$\mathrm{H} 3$ & .28 & 1.95 & Rejected \\
\hline${ }^{\mathrm{a}} p<.01$ (based on $t_{(23)}$, two-tailed test). $t_{(0.01 ; 23)}=3.10$. &
\end{tabular}

construct's maximal correlation with other constructs (Chin, 1998). Under this constraint, only the correlation between behavior regulation and academic performance (.80) was marginally larger than the square root of the behavior regulation AVE (.79). The fit estimates are presented in Tables 3 and 4 . In summary, the evaluation of the measurement model showed good reliability and validity.

\subsubsection{Evaluation of the structural model}

The structural model evaluated the relationship between behavior regulation and adaptation to school by examining the path coefficients $(\beta)$. The amount of variance in the endogenous construct explained by the model $\left(R^{2}\right)$ was used as a measurement of the predictive power of exogenous latent variables. The model explained $74 \%$ of the variance of academic performance $\left(R^{2}=.737\right)$, and $34 \%$ of the classroom behavior $\left(R^{2}=.337\right)$. According to Chin (1998), the explained variance of the academic performance was substantial, whereas the explained variance of the classroom behavior was moderate. Table 5 shows the hypotheses, path coefficients $(\beta)$, and $t$-values. Path coefficients $(\beta)$ and $R^{2}$ values are summarized in Fig. 1

Specifically, the relative impact of an exogenous latent variable on the endogenous latent variable can be examined by comparing the change in its $R^{2}$ value when the exogenous variable is removed from the model. Chin (1998) suggested values of $0.02,0.15$, and 0.35 as operational definitions of small, medium, and large effect sizes $\left(f^{2}\right)$, respectively. Effect sizes are presented in Table 6. The evaluation of the structural model supported our hypotheses that behavior regulation in kindergarten would be positively related to academic performance $(\mathrm{H} 1)$ and negatively related to behavior problems in the classroom (H2) by the end of first grade. The results were demonstrated with simultaneous consideration of nonverbal intelligence and mother's level of education, as significant correlations were found in preliminary analyses. The effect size $\left(f^{2}\right)$ of nonverbal intelligence on academic performance was moderate (.18) compared to the large effect of behavior regulation (.62). However, we did not find evidence that classroom behavior was significantly related to academic performance (H3).

Additionally, we tested the alternative explanation that the relationships among the observed variables could be influenced by extreme data points by following the procedure of regression diagnostics (Belsky, Kuh, \& Welsch, 1980; Cook \& Weisberg, 1982). One observation was identified as an influential observation. The structural model results were confirmed without this observation.

\section{Discussion}

This study aimed to examine the influence of kindergarten children's behavior regulation on their adjustment to school, focusing

Table 4

Discriminant validity coefficients.

\begin{tabular}{|c|c|c|c|c|c|}
\hline & Behavior regulation & Nonverbal intelligence & Academic performance & Classroom behavior & Mother's education \\
\hline Behavior regulation & .79 & & & & \\
\hline Nonverbal intelligence & .46 & 1.00 & & & \\
\hline Academic performance & .80 & .55 & .87 & & \\
\hline Classroom behavior & .50 & .15 & .59 & .86 & \\
\hline Mother's education & .10 & -.13 & .05 & .34 & 1.00 \\
\hline
\end{tabular}

Note. The principal diagonal elements correspond to the square root of the average variance extracted (AVE) of each construct.

Off-diagonal elements are correlations between the constructs. 

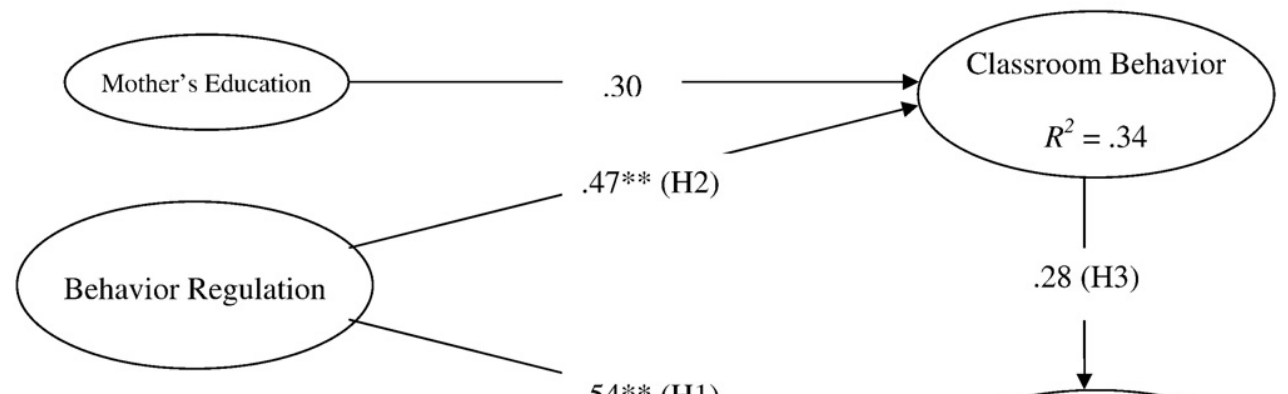

$.54 * *(\mathrm{H} 1)$

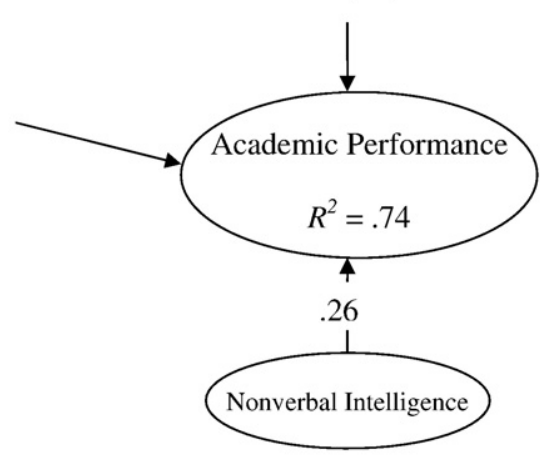

Data collection at T1 (kindergarden)

Data collection at T2 (first grade)

Fig. 1. Structural model results: The relations of behavior regulation to academic achievement and classroom behavior. Note. $* * p<.01$ (based on $t_{(23)}$, two-tailed test). $t_{(0.01 ; 23)}=3.10$.

on both academic and social outcome indicators. In line with previous findings (Eisenberg et al., 2000; Howse, Lange, Farran, \& Boyles, 2003), early behavior regulation was positively related to academic performance and classroom behavior in school. Moreover, the results demonstrated the relative importance of behavior regulation above and beyond intelligence for academic progress even at a very early age, and thereby contribute to the recent controversial discussion on preconditions of academic success (Bayer \& Gollwitzer, 2007; Duckworth \& Seligman, 2005; Huang \& Vazsonyi, 2008). However, the small sample size calls for some caution about the external validity of results. The relationships among the observed variables may be sample specific and thus not be representative for the population of children from which the sample was drawn.

Unexpectedly, classroom behavior was not related to academic performance. This may be explained by the nature of first grade classroom environment, which is mostly characterized by a playful atmosphere. Classroom behavior, and behavior problems in particular, may be linked to academic underachievement as school becomes more demanding (Ladd \& Burgess, 2001). However, the lack of significant findings may be caused by sample characteristics and measurement approach. Also, the relationship between classroom behavior and academic performance may not be causal but bidirectional, which could not have been tested with PLS.

Moreover, individual differences in children's early behavior regulation may influence not only their adaptation to school but also how their teachers and peers perceive them (Hughes, Luo, Kwok, \& Loyd, 2008; Rothbart \& Jones, 1998). The present study relied on teacher reports of academic performance and classroom behavior. However, no interpretations about the bidirectional interplay be-

Table 6

Effect sizes.

\begin{tabular}{llll}
\hline Exogenous variable & Endogenous variable & \multicolumn{2}{c}{ Effect size } \\
\cline { 3 - 4 } & & $f^{2}$ & \\
\hline Behavior regulation & Academic performance & .62 & Large \\
Nonverbal intelligence & Academic performance & .18 & Medium \\
Classroom behavior & Academic performance & .21 & Medium \\
Behavior regulation & Classroom behavior & .33 & Medium \\
Mother's education & Classroom behavior & .12 & Small \\
\hline
\end{tabular}

tween the child's characteristics and the child's interaction with teachers and peers are possible. Further research should include classroom observations to investigate the complex interactions in the school environment. Additional limitations suggest a tentative interpretation of the path model results. Finally, the sample size was rather small and the children came from a middle-class socioeconomic background. Therefore, these results cannot be generalized to a larger population. A replication of the findings with a larger and more diverse sample is desirable.

However, this study has important methodological strengths. Children's behavior regulation was measured by two different observational situations. Outcome indicators for school success included both teacher evaluations and standardized performance tests. Children's behavior regulation was positively related to academic performance and classroom behavior. Individual differences may persist as selfregulated learning becomes more important (Boekaerts \& Corno, 2005; Corno, 2008). Improving early behavior regulation skills may therefore become an important feature of early intervention in order to facilitate children's successful transition and adjustment to school.

\section{References}

Barklay, D., Higgins, C., \& Thompson, R. (1995). The Partial Least Squares (PLS) approach to causal modelling: Personal computer adoption and use as an illustration. Technology Studies: Special Issue on Research Methodology, 2, 285-309.

Bayer, U., \& Gollwitzer, P. M. (2007). Boosting scholastic test scores by willpower: The role of implementation intentions. Self and Identity, 6, 1-19.

Belsky, D. A., Kuh, E., \& Welsch, R. E. (1980). Regression diagnostics. New York: Wiley.

Boekaerts, M., \& Corno, L. (2005). Self-regulation in the classroom: A perspective on assessment and intervention. Applied Psychology: An International Review, 54, 199-231.

Bulheller, S., \& Häcker, H. (2002). Coloured progressive matrices, (3rd ed.). Frankfurt, Germany: Hartcourt

Calkins, S. D., \& Howse, R. B. (2004). Individual differences in self-regulation: Implications for childhood adjustment. In P. Philippot \& R. S. Feldman (Eds.), The regulation of emotion (pp. 307-322). Mahwah, NJ: Erlbaum.

Carmines, E. G., \& Zeller, R. A. (1979). Reliability and validity assessment. Beverly Hills, CA: Sage.

Chin, W. W. (1998). The Partial Least Squares approach to structural equation modelling. In G. A. Marcoulides (Ed.), Modern methods for business research (pp. 295-336). Mahwah, NJ: Erlbaum.

Cook, R. D., \& Weisberg, S. (1982). Residuals and influence in regression. New York: Chapman \& Hill.

Corno, L. (2008). Work habits and self-regulated learning: Helping students to find a 'will' from a 'way'. In D. H. Schunk \& B.J. Zimmerman (Eds.), Motivation and self- 
regulated learning: Theory, research, and applications (pp. 197-222). Mahwah, NJ: Erlbaum.

Deary, I. J., Strand, S., Smith, P., \& Fernandes, C. (2007). Intelligence and educational achievement. Intelligence, 35, 13-21.

Duckworth, A. L., \& Seligman, M. E. P. (2005). Self-discipline outdoes IQ in predicting academic performance of adolescents. Psychological Science, 16, 939-944.

Eisenberg, N., Guthrie, I. K., Fabes, R. A., Shephard, S., Losoya, S., Murphy, B. C., et al. (2000). Prediction of elementary school children`s externalizing problem behaviors from attentional and behavioral regulation and negative emotionality. Child Development, 71, 1367-1382.

Fantuzzo, J., Bulotsky-Shearer, R., McDermott, P. A., McWayne, C., Frye, D., \& Perlman, S. (2007). Investigation of dimensions of social-emotional classroom behaviour and school readiness for low-income urban preschool children. School Psychology Review, 36, 44-62.

Fornell, C., \& Larcker, D. F. (1981). Evaluating structural equation models with unobservable variables and measurement error. Journal of Marketing Research, 18, 39-50.

Garon, N., Bryson, S. E., \& Smith, I. M. (2008). Executive function in preschoolers: A review using an integrative framework. Psychological Bulletin, 134, 31-60.

Goldsmith, H. H. Reilly, J. Lemery, K. S., Longley, S., \& Prescott, A. (1993). The Laboratory Temperament Assessment Battery (Preschool Version 0.5): Technical report Madison: Department of Psychology, University of Wisconsin.

Goodman, R. (1997). The Strengths and Difficulties Questionnaire: A research note. Journal of Child Psychology and Psychiatry, 38, 581-586.

Grimm, H., \& Schöler, H. (1991). Heidelberger Sprachentwicklungstest HSET [Heidelberger Test of Language Development HSET], (2nd ed.). Braunschweig, Germany: Westermann.

Howse, R. B., Lange, G., Farran, D. C., \& Boyles, C. D. (2003). Motivation and selfregulation as predictors of achievement in economically disadvantaged young children. The Journal of Experimental Education, 71, 151-174.

Huang, L., \& Vazsonyi, A. T. (2008, March). Self-control, intelligence, and academic achievement: Does grit matter more? Poster presented at the 12th Biennal Meeting of the Society for Research on Adolescence (SRA), Chicago, USA.

Hughes, J. N., Luo, W., Kwok, O. -M., \& Loyd, L. K. (2008). Teacher-student support effortful engagement, and achievement: A 3-year longitudinal study. Journal of Educational Psychology, 100, 1-14.

Jarvis, C. B., Mackenzie, S. B., \& Podsakoff, P. M. (2003). A critical review of construct indicators and measurement model misspecification in marketing and consumer research. Journal of Consumer Research, 30, 199-218.

Klasen, H., Woerner, W., Rothenberger, A., \& Goodman, R. (2003). Die deutsche Fassung des Strengths and Difficulties Questionnaire (SDQ-Deu)-Übersicht und Bewertung erster Validierungs- und Normierungsbefunde [The German version of the Strengths and Difficulties Questionnaire (SDQ-Ger): Overview over first validation and normative studies]. Praxis Kinderpsychologie Kinderpsychiatrie, 52, 491-502.

Kniveton, B. H. (1998). Underachieving boys: A case for working harder or boosting self-confidence? Emotional \&' Behavioural Difficulties, 3, 23-28.

Kopp, C. (1982). Antecedents of self-regulation: A developmental perspective. Developmental Psychology, 18, 199-214.

Krajewski, K. Küspert, P. \& Schneider W. (2002). DEMAT1 + : Deutscher Mathematiktest für erste Klassen [DEMAT1+: German Test of Mathematics for the $1^{\text {st }}$ Grade]. Göttingen, Germany: Beltz.

Ladd, G. W., \& Burgess, K. B. (2001). Do relational risks and protective factors moderate the linkages between childhood aggression and early psychological and school adjustment? Child Development, 72, 1579-1601.

Landerl, K., Wimmer, H., \& Moser, E. (1997). SLRT: Salzburger Lese- und Rechtschreibtest [SLRT: Salzburger Reading and Writing Test]. Bern, Switzerland: Huber.

Magnuson, K. (2007). Maternal education and children's academic achievement during middle childhood. Developmental Psychology, 43, 1497-1512.
McClelland, M. M., Cameron, C. E., Connor, C. M., Farris, C. L., Jewkes, A. M. \& Morrison, F. J. (2007). Links between behavioural regulation and preschoolers' literacy, vocabulary, and math skills. Developmental Psychology, 43, 947-959.

McClelland, M. M., Morrison, F. J., \& Holmes, D. L. (2000). Children at risk for early academic problems: The role of learning-related social skills. Early Childhood Research Quarterly, 15, 307-329.

Mischel, W., Shoda, Y., \& Rodriguez, M. L. (1989). Delay of gratification in children. Science, 244, 933-938.

Nelson, J. R., \& Stage, S. A. (2007). Fostering the development of vocabulary knowledge and reading comprehension though contextually-based multiple meaning vocabulary instruction. Education and Treatment of Children, 30, 1-22.

Nunnally, J. (1978). Psychometric theory, (3rd ed.). New York: McGraw-Hill.

Organization for Economic Co-operation and Development (1999). Classifying educationa programmes: Manual for ISCED-97 implementation in OECD countries. Retrieved December 4, 2007 from http://www.oecd.org/dataoecd/7/2/1962350.pdf

Petriwskyj, A., Thorpe, K., \& Tayler, C. (2005). Trends in construction of transition to school in three western regions, 1990-2004. International Journal of Early Years Education, 13, 55-69.

Ponitz, C. E., McClelland, M. M., Connor, C. M., Jewkes, A. M., Farris, C. L., \& Morrison, F. J. (2008). Touch your toes! Developing a direct measure of behavioral regulation in early childhood. Early Childhood Research Quarterly, 23, 141-158.

Preckel, F., Holling, H., \& Vock, M. (2006). Academic underachievement: Relationship with cognitive motivation, achievement motivation, and conscientiousness. Psychology in the Schools, 43, 401-411.

Rabiner, D. L., Murray, D. W., Schmid, L., \& Malone, P. S. (2004). An exploration of the relationship between ethnicity, attention problems, and academic achievement. School Psychology Review, 33, 498-509.

Raven, J. C., Court, J. H., \& Raven, J. (1984). Coloured progressive matrices: Booklet of test items and manual. London: Lewis.

Ringle, C. M., Wende, S., \& Will, A. (2005). SmartPLS 2.0 (beta). Hamburg, Germany: University of Hamburg

Rothbart, M. K., \& Jones, L. B. (1998). Temperament, self-regulation, and education. School Psychology Review, 27, 479-491.

Spinrad, T. L., Eisenberg N. Cumberland, A., Fabes, R. A., Valiente, C, Shephard, S. A. et al. (2006). Relation of emotion-related regulation to children's social competence: A longitudinal study. Emotion, 6, 498-510.

Suchodoletz, A. v., Trommsdorff, G., \& Heikamp, T. (submitted for publication). Maternal warmth and responsiveness in the development of children's self-regulation. Social Development.

Trommsdorff, G. (in press). Socialization of self-regulation for achievement in cultura context: A developmental-psychological perspective on the Asian miracle. In U. Kim \& Y.-S. Park (Eds.), Asia's educational miracle: Psychological, social, and cultural perspectives. New York: Springer.

Warnick, E. M., Bracken, M. B., \& Kasl, S. (2008). Screening efficiency of the Child Behavior Checklist and Strengths and Difficulties Questionnaire: A systematic review. Child and Adolescent Mental Health, 13, 140-147.

Woerner, W., Becker, A., Friedrich, C., Klasen, H., Goodman, R., \& Rothenberger, A. (2002). Normierung und Evaluation der deutschen Elternversion des Strengths and Difficulties Questionnaire (SDQ): Ergebnisse einer repräsentativen Felderhebung [Normative data and evaluation of the German parent-rated Strengths and Difficulties Questionnaire (SDQ): Results of a representative field study]. Zeitschrift für Kinder- und Jugendpsychiatrie und Psychotherapie, 30, 105-112.

Yung, Y. -F., \& Chan, W. (1999). Statistical analyses using bootstrapping: Concepts and implementation. In R. H. Hoyle (Ed.), Statistical strategies for small sample research (pp. 81-105). London: Sage. 